\title{
What are kids getting into these days? A retrospective chart review of substance use presentations to a Canadian pediatric emergency department
}

\author{
G. Emmi Driedger, $\mathrm{MD}^{* \dagger}$; Kathryn A. Dong, MSc, $\mathrm{MD}^{\dagger \neq}$; Amanda S. Newton, $\mathrm{PhD}, \mathrm{RN}^{* \star \S}$; \\ Rhonda J. Rosychuk, $\mathrm{PhD}^{* \dagger \S}$; Samina Ali, $\mathrm{MDCM}^{* \dagger \S}$
}

\section{ABSTRACT}

Objectives: Goals for this study were to characterize the substances being used by youth who presented to an emergency department (ED), their demographic descriptors, and to describe the associated acute morbidity and mortality.

Methods: We conducted a retrospective review of all youth, ages 10-16 years, who presented to a pediatric ED with complaints related to recreational drug use $(n=641)$ for 2 years ending on December 31, 2009.

Results: The median age of patients was 15 years; $56 \%$ were female. Six percent of patients were homeless, and $21 \%$ were wards of the state. The most frequent ingestions included ethanol $(74 \%)$, marijuana $(20 \%)$, ecstasy $(19 \%)$, and medications (15\%). Over one third of patients had ingested two or more substances. Ninety percent of patients were brought to the ED by the emergency medical services; $63 \%$ of these activations were by non-acquaintances. Of the $47 \%$ of youth who presented with a decreased level of consciousness, half had a Glasgow Coma Scale less than 13. The Canadian Triage and Acuity Scale score was 1 or 2 for $44 \%$ of patients. Sixtyeight percent received IV fluids, $42 \%$ received medication, and $4 \%$ were intubated. The admission rate was $9 \%$.

Conclusions: Youth who presented to the ED for substance use represented a socially vulnerable population whose use of recreational substances resulted in high medical acuity and significant morbidity. Improved clinical identification of such high-risk youth and subsequent design of interventions to address problematic substance use and social issues are urgently needed to complement the acute medical care that youth receive.

\section{RÉSUMÉ}

Objectifs: L'étude décrite ici avait pour buts de caractériser les drogues utilisées par les jeunes traités dans un service des urgences (SU), de relever les descripteurs démographiques et de décrire la morbidité et la mortalité aiguës, associées à cette utilisation.

Méthode: Les auteurs ont procédé à un examen rétrospectif des dossiers médicaux de tous les jeunes âgés de 10 à 16 ans, qui ont été traités dans un service des urgences pédiatriques pour des troubles liés à la consommation de drogues à usage récréatif ( $n=641$ ), sur une période de 2 ans, se terminant le 31 décembre 2009.

Résultats: L'âge médian était de 15 ans, et $56 \%$ des malades étaient de jeunes filles. Dans $6 \%$ des cas, il s'agissait de sansabris, et $21 \%$ des patients étaient sous la tutelle de l'État. Les drogues le plus souvent consommées étaient l'alcool éthylique $(74 \%)$, la marijuana $(20 \%)$, l'ecstasy $(19 \%)$ et les médicaments (15\%). Dans plus du tiers des cas, les personnes avaient fait usage d'au moins deux drogues. Quatre-vingt-dix pour cent des jeunes ont été transportés au SU par les services médicaux d'urgence et, dans $63 \%$ des cas, les appels avaient été faits par des inconnus. Parmi les $47 \%$ de jeunes souffrant d'une altération de l'état de conscience, la moitié avait une cote inférieure à 13 sur l'échelle de Glasgow. Par ailleurs, 44\% des patients ont obtenu une cote de 1 ou 2 sur l'Échelle canadienne de triage et de gravité. Enfin, il y a eu administration de liquides par voie intraveineuse dans $68 \%$ des cas et de médicaments dans $42 \%$ des cas, et intubation dans $4 \%$ des cas; le taux d'hospitalisation s'est élevé à $9 \%$.

Conclusions: Les jeunes traités au SU pour consommation de drogues faisaient partie d'une population socialement vulnérable, chez qui la prise de drogues à usage récréatif s'est soldée par des troubles graves, nécessitant des soins médicaux d'urgence. Aussi une meilleure reconnaissance clinique de ces jeunes fortement prédisposés et, par la suite, l'élaboration d'interventions visant à régler le problème de la consommation de drogues et les difficultés sociales s'imposent-elles avec acuité afin de compléter les soins médicaux actifs que reçoivent ces enfants et adolescents.

Keywords: pediatric, substance abuse, adolescent, drug abuse, emergency

From the *Department of Pediatrics; †Faculty of Medicine \& Dentistry; $¥$ Department of Emergency Medicine, University of Alberta, Edmonton, AB; and §Women and Children's Health Research Institute, Edmonton, AB.

Correspondence to: Dr. Samina Ali, Department of Pediatrics, Edmonton Clinic Health Academy, 11405 - 87 Avenue, Edmonton, AB T6G 1C9; Email: sali@ualberta.ca 


\section{INTRODUCTION}

Substance use among youth in Canada is alarmingly prevalent. Canadian data indicate that $45 \%$ of students in grades 7-12 have consumed alcohol and that $33 \%$ of students have engaged in binge drinking. ${ }^{1}$ The mean age at first alcohol use has been reported as 12.8 years. ${ }^{1}$ Use of cannabis in the last 12 months in this same population was $21 \%$; in addition, $5 \%$ had used ecstasy, $5 \%$ psychoactive chemicals (such as sedatives, stimulants, or pain relievers), 5\% dextromethorphan, and $4 \%$ hallucinogens with the intent to "get high" within the past 12 months. ${ }^{1}$ Prescription drug abuse is also becoming increasingly common, and youth have been identified as a high-risk group for misuse and associated harms., ${ }^{2,3}$

The morbidity and mortality associated with substance use is well described. ${ }^{4}$ Use of alcohol and illicit substances can result in serious harm, including physical injury, psychosis, loss of consciousness, and death due to cardiopulmonary collapse. ${ }^{5,6}$ A 2003 Canadian study of emergency department (ED) visits found that 3.1\% of visits for injuries by patients ages 15-19 years were alcohol-related. ${ }^{5}$ Substance use is also associated with increased risk of sexual assault, unplanned sexual activity, behavioural problems, pregnancy, and selfharm. ${ }^{6-13}$ Use of more than one type of substance at the same time (termed polydrug use) is associated with a further increased risk of harm, injury, and overdose. ${ }^{14}$ Emerging evidence suggests that the overall incidence of polydrug use and associated drug-related death is increasing; however, Canadian data are limited. ${ }^{12,13}$

The ED often serves as an entry point of care for children with acute substance use related medical or psychological issues. ${ }^{5,15}$ As such, the initial medical management and subsequent psychosocial needs of these at-risk youth often fall to the hands of the emergency physician. The objectives of our study were to 1) characterize the substances being used by youth who presented to a pediatric ED for complaints related to their substance use, 2) characterize the demographic descriptors of these youth, and 3) describe the acute morbidity and mortality associated with this substance use.

\section{MATERIALS AND METHODS}

\section{Setting}

This retrospective cohort study was conducted at the Stollery Children's Hospital in Edmonton, Alberta (population 817,498). ${ }^{16}$ This tertiary care centre provided services to children ages 0 to 16 years, with a catchment area including Northern Alberta and parts of British Columbia, Saskatchewan, the Northwest Territories, Yukon, and Nunavut. The pediatric ED with 12 pediatric beds had a yearly census of approximately 24,000 patients during the study period. It was staffed by over 20 physicians, most of whom were pediatric emergency, residency-trained.

\section{Case identification}

We included all consecutive cases of acute intoxication and unintentional poisoning in children ages 10 to 16 years who presented to the Stollery ED from January 1, 2007, to December 31, 2009. Cases were identified if their primary or secondary recorded diagnoses were coded according to the World Health Organization International Classification of Diseases, Tenth Revision (ICD-10), as any of the following: F10-19 with subsets 0.0, 0.1, 0.3, 0.4, 0.5, 0.6, 0.7, 0.8, 0.9, T36.*. - 50.*, T51.* $65 . *$, X40.* $49 . *$, Y10.* $19^{*}$ (Table 1). We excluded cases of ingestion for intent of suicide or selfharm; accidental ingestions were also excluded, if this intention was explicitly stated in the chart. Multiple visits by the same child were recorded as separate visits. The University of Alberta Hospital Health Research Ethics Board granted ethics approval prior to implementation of the study.

\section{Data collection}

Medical records (paper-based) were reviewed between August 2010 and February 2011; this included a review of documentation by all health professionals involved in the patient's care, as well as the results of all investigations performed during the given health care encounter. The following variables were collected from each record: demographic characteristics, past medical history of substance use and mental health disorders, guardianship status, substance(s) used, mode of arrival to the ED, Canadian Triage and Acuity Scale (CTAS) coding, ${ }^{17}$ presenting complaint, level of consciousness, admission status, medications and treatments provided by emergency medical services (EMS) or ED personnel, consultation with a social worker or mental health professional, and time of contact with various health professionals. The list of specific substances ingested were extracted from the chart, because they were 


\begin{tabular}{|c|c|}
\hline ICD-10 classification code & Description of diagnosis \\
\hline F10-19 & $\begin{array}{l}\text { Mental and behavioural disorders due to use of } \\
\text { a. Alcohol } \\
\text { b. Opioids } \\
\text { c. Cannabinoids } \\
\text { d. Sedatives \& hypnotics } \\
\text { e. Cocaine } \\
\text { f. Other stimulants, including caffeine } \\
\text { g. Hallucinogens } \\
\text { h. Tobacco } \\
\text { i. Volatile substances } \\
\text { j. Multiple drug use and use of other psychoactive substances }\end{array}$ \\
\hline T36-50 & Poisoning by, adverse effect of, and underdosing of drugs, medicaments, and biological substances \\
\hline T51-65 & Toxic effects of substances chiefly nonmedicinal as to source \\
\hline X40-49 & Accidental poisoning by and exposure to noxious substances \\
\hline Y10-19 & $\begin{array}{l}\text { Poisoning by and exposure to } \\
\text { a. Nonopioid analgesics, antipyretics, and antirheumatics } \\
\text { b. Antiepileptic, sedative-hypnotic, antiparkinsonism, and psychotropic drugs, not elsewhere classified } \\
\text { c. Narcotics and psychodysleptics (hallucinogens), not elsewhere classified } \\
\text { d. Other drugs acting on the autonomic nervous system } \\
\text { e. Other and unspecified drugs, medications, and biological substances } \\
\text { f. Alcohol } \\
\text { g. Organic solvents and halogenated hydrocarbons and their vapours } \\
\text { h. Other gases and vapours } \\
\text { i. Pesticides } \\
\text { j. Other and unspecified chemicals and noxious substances }\end{array}$ \\
\hline
\end{tabular}

described in the documented medical or nursing history; if available, toxicologic blood and urine tests were included as well. Data were recorded in a study-specific standardized, electronic abstraction form that was managed using Research Electronic Data Capture (REDCap), an electronic data capture tool hosted and supported by the Clinical Research Informatics Core in the Women and Children's Health Research Institute (Edmonton, Alberta). ${ }^{18}$

Approximately half of the medical records were abstracted by an experienced research assistant (YK), who was trained by the first author (ED); the research assistant was blinded to the study hypotheses. Due to financial constraints, the remaining records were abstracted by the first author, who was not blinded to the hypotheses. The research assistant and first author met frequently and regularly during the data abstraction phase.

Conditions recorded as mental health disorders included anxiety and mood disorders, attention deficit and hyperactivity disorder, oppositional defiant disorder, conduct disorder, schizophrenia, fetal alcohol syndrome, previous suicidality, and any previous or ongoing psychiatric care for any reason. A patient was considered a ward of the state if he or she were under a temporary or permanent government order, or described as being under foster care. Those who were a ward of the state were treated as not having a social work consult requested (despite the automatic involvement of such services in our ED), in order to capture the rate of "new" social work consultations. Significant head injury was defined as a skull fracture, intracranial bleed, concussion, or loss of consciousness (if health care professionals felt it to be due to head trauma rather than intoxication). Data that were missing or unclear to the abstractors were both treated as missing, and the associated denominators were adjusted; missing data were not imputed in this study. 


\section{Data analyses}

Statistical analyses were performed using SAS 9.2 software by SAS Institute Inc., Cary, NC, USA. Associations between substance use and categorical variables (i.e., gender, age group) were detected using chi-square and Fisher's exact tests. Logistic regression was used to determine the association of psychosocial factors with ward of the state, and odds ratios were calculated with $95 \%$ Wald confidence intervals. A p-value $<0.05$ was considered statistically significant. Because of overlap in substance use, associations for specific substances were calculated for single-drug ingestions only.

\section{RESULTS}

A total of 972 charts were potentially eligible for inclusion. This sample represented $1.3 \%$ of ED visits $(972 / 73,166)$ over the study time period. Three hundred and eleven charts (32\%) met the exclusion criteria, and 20 charts $(2.1 \%)$ could not be located or were unreadable due to errors in microfiche processing. Thus, 641 charts were available for abstraction, including 30 charts $(4.7 \%)$ that had incomplete data due to the patient leaving the ED prematurely.

\section{Demographic data}

The median age of our study population was 15 years (interquartile range [IQR] 14-16) with $63.2 \%$ ( $n=405 / 641)$ between the ages of $13-15$ years. A total of $8 \%(n=53 / 641)$ of patients presented to the ED more than once; of these, $75 \%(n=40 / 53)$ presented twice, whereas the remaining 13 presented between three and nine times during the study period. The psychosocial determinants of health are presented in Table 2.

\section{Presentation to the emergency department}

Over $90 \%$ of patients arrived via EMS (575/641), including $4.2 \%(24 / 575)$ who had been transferred from another facility. The remaining minority arrived via personal vehicle, police services vehicle, or by foot. For those who arrived via ambulance, with EMS documentation provided (407/575), 63\% were activated by non-acquaintances (e.g., bystanders, police, building security, public transit operators). During the study timeframe, patients arrived to the ED accompanied by a family member $(26.3 \%, 168 / 640)$, police $(17.0 \%, 109 /$ $640)$, friend/partner $(4.2 \%, 27 / 640)$, case worker/social worker $(3.8 \%, 24 / 640)$, or unaccompanied aside from EMS personnel $(48.8 \%, 312 / 640)$.

The CTAS scores in our study population were as follows: Resuscitation (1) $=4.4 \%(28 / 637)$, Emergent $(2)=55.6 \%(354 / 637)$, Urgent $(3)=27.6 \%(176 / 637)$, Less Urgent $(4)=12.2 \%(78 / 637)$, and Non-Urgent $(5)=0.2 \%$ (1/637). Presenting complaints included decreased level of consciousness (47\%, 300/635), erratic, aggressive or unusual behaviour (177/635), injury or assault $(17 \%, 109 / 635)$, nausea or vomiting (15\%, 94/ $635)$, and a variety of other subjective complaints, including hallucinations, palpitations, and dizziness $(28 \%, 175 / 635)$.

Of those who had a decreased level of consciousness documented, the Glasgow Coma Score (GCS) was recorded as 3 for $3.5 \%$ (10/285), 4 to 8 for $20 \%$ (57/285), 9 to 12 for $27 \%(77 / 285), 13$ or 14 for $31.2 \%$ $(89 / 285)$, and 15 for $18.2 \%(52 / 285)$. Of those who were assaulted (60/641), 70\% (42/60) were physically assaulted, and $26.7 \%(16 / 60)$ were sexually assaulted. Injuries sustained included minor head injuries $(68 \%$, 98/145), significant head injuries (10\%, 14/145), lacerations $(7 \%, 10 / 145)$, fractures $(4 \%, 6 / 145)$, superficial abrasions and/or bruising (18\%, 26/145), and other complaints, which included stabbing, spinal cord injury, and pneumothorax (11\%, 16/145).

\section{Substances of abuse}

Specific ingestion patterns are presented in Figure 1. Of the cough/cold medications, 32\% (7/22) contained dextromethorphan, and 50\% (11/22) were of the brand name Coricidin. Other top cough/cold preparations ingested included Vicks Nyquil $(n=2)$, Robitussin $(n=2)$, and Benylin $(n=1)$. Single-drug ingestions occurred in $66.6 \%$ of cases $(426 / 640)$, whereas polydrug ingestions occurred in $33.4 \%$ (214/640). Although more ingestions of ethanol were single rather than polydrug ingestions ( $n=300$ v. $n=170$, respectively), the opposite was true for all other substances. In the cases where the source of the substance(s) could be determined from the chart, disclosed sources included party or peers $(n=279 / 331)$, family member or family member's prescription $(n=28 / 331)$, drug dealer (14/331), or own prescription (10/331). Table 3 outlines the specific prescription drugs reported as used by patients included in our study. 


\begin{tabular}{lc|}
\hline Table 2. Demographic characteristics \\
\hline Demographic & $n(\%)$ \\
\hline Age $(n=641)$ & $36(5.6)$ \\
$\quad 10$ to 12 years & $405(63.2)$ \\
13 to 15 years & $200(31.2)$ \\
16 years & \\
Gender ( $n=641)$ & $359(56.0)$ \\
$\quad$ Female & \\
Psychosocial determinants of health & $193(31.0)$ \\
$\quad$ Pre-existing substance abuse $(n=623)$ & $102(16.5)$ \\
$\quad$ Pre-existing mental health disorder $(n=618)$ & $132(20.9)$ \\
Ward of the state $(n=632)$ & $41(6.4)$ \\
Homeless $(n=641)$ &
\end{tabular}

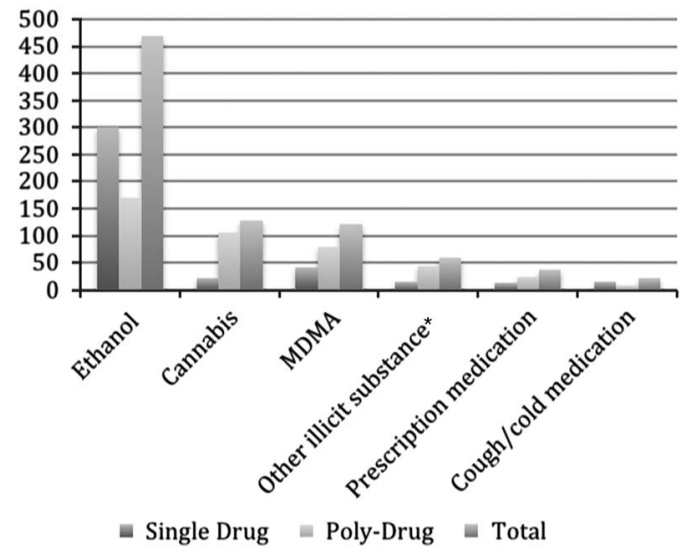

Figure 1. Substances Abused by Patients Presenting to the Pediatric Emergency Department $(n=640)$.

*Included crack cocaine, GHB, heroin, mushrooms, and ketamine.

\section{Emergency management}

Specific interventions provided by EMS or in the ED included IV fluids $67.9 \%$ (423/623), medications $41.6 \%$ (259/623), intubation $3.5 \%(22 / 623)$, and chest compressions $0.2 \%$ (1/623). The provincial poison control centre was contacted in $3.6 \%(22 / 623)$ of all cases. Nine percent of patients (57/623) were admitted; of these, one third were admitted to the pediatric intensive care unit (PICU). In the PICU, another 2 were intubated, and 1 was placed on extracorporeal membrane oxygenation. Of all admissions, $14.6 \%$ $(31 / 213)$ were for polydrug ingestions, whereas $6.4 \%(26 / 408)$ were for single drug ingestions. The admission rate per substance is presented in Figure 1.

\section{Patient disposition}

The median length of stay in the ED was 4.58 hours (IQR 4.45 to 4.93). The median length of stay for admitted patients was 2 days (range: $1-3$ ). Thirty-two percent of non-ward of the state patients $(161 / 509)$ received a new consultation from the ED social worker, and $12.6 \%$ (78/619) had a mental health consultation performed in the ED or requested as an outpatient. Other follow-up appointments (not including mental health) were booked for $18 \%$ (111/619) of patients. Two deaths were captured during our study period, and both occurred in the PICU, after the patient had left the ED; both patients had ingested methylenedioxymethamphetamine (MDMA).

\section{Demographic trends and correlations}

Age: Younger age ( $<16$ years old) was associated with use of cannabis $(72.7 \%, 16 / 22)$, prescription medications $(69.2 \%, 9 / 13)$, and cough/cold medications $(85.7 \%, 12 / 14)$, whereas older age $(\geq 13$ years old) was associated with the use of alcohol $(96 \%, 288 / 300)$, MDMA (95.1\%, 39/41), and other illicit substances $(100 \%, 15 / 15)$. This overall association between age and specific single-drug ingestion $(n=405)$ was statistically significant $(p=0.048)$.

Sex: Female patients tended to use more MDMA $(68.3 \%, 28 / 41)$ and alcohol $(57.3 \%, 172 / 300)$, whereas male patients used more of all other substances (e.g., cannabis) $(63.6 \%, 14 / 22)$, other illicit substances $(60 \%, 9 / 15)$, prescription medications $(61.5 \%, 8 / 13)$, and cough and cold medications $(57.1 \%, 8 / 14)$. However, none of the associations between sex and specific single-drug ingestions $(n=405)$ were statistically significant $(p=0.067)$.

GCS: Lower presenting GCS $(\leq 12)$ was seen with use of ethanol $(57.1 \%, 100 / 175)$, whereas higher presenting GCS (13-15) was seen with use of cannabis (83.3\%, 5/6), MDMA $(100 \%, 1 / 1)$, other illicit substances $(66.7 \%, 2 / 3)$, and cough/cold medications $(66.7 \%, 2 / 3)$. However, the overall association between GCS and single-drug ingestion $(n=196)$ was not statistically significant $(p=0.227)$.

Admission to hospital: Overall, hospital admission $(n=22 / 405)$ was associated with specific single-drug ingestions $(p<0.001)$. Hospital admission was also associated with polydrug use, with $14.6 \%(n=31 / 214)$ of those with polydrug ingestion being admitted versus 


\begin{tabular}{|lr|}
\hline $\begin{array}{l}\text { Table 3. Prescription medications of abuse }(\boldsymbol{n}=\mathbf{3 7} \text { patients; } \\
\text { multidrug ingestions were possible and noted) }\end{array}$ & $n$ \\
\hline Medications & 11 \\
\hline Antidepressants & 11 \\
Benzodiazepines & 9 \\
Opioid-containing preparations & 7 \\
Antipsychotics & 5 \\
Stimulants & 5 \\
Antiepileptics & 3 \\
Antihypertensives & 5 \\
Other* & 5 \\
\hline *Includes naproxen, ranitidine, quinine, oral contraceptives, and diabetes medication.
\end{tabular}

$6.1 \%(n=26 / 426)$ of those with single-drug ingestion $(p=0.001)$.

Assault and injury: Overall, sustaining a physical injury $(10.7 \%, 43 / 403)$ was associated with the ingestion of single-specific substances $(p<0.001)$. Ethanol ingestion was associated with more physical injury, whereas all other substances were associated with less injury.

Psychosocial factors: In our study population, those who admitted to a previous substance abuse problem $(31 \%, 193 / 622)$ (odds ratio $[\mathrm{OR}]=1.8$, CI 1.2-2.7, $p=0.004)$ and those who reported homelessness $(6.4 \%$, 41/639) (OR $=2.9$, CI 1.5-5.6, $p=0.002)$ were more likely to be wards of the state $(20.9 \%, 132 / 632)$. In addition, those who disclosed a pre-existing mental health problem $(16.1 \%, 102 / 619)$ were more likely to claim homelessness $(6.4 \%, 41 / 639) \quad(\mathrm{OR}=2.8$, CI $1.4-5.6, p=0.005)$. There was no significant increase in risk of polydrug ingestion with age, previous substance use history, mental health condition, being a ward of the state, or homeless.

\section{DISCUSSION}

The ED represents a key point of health care system access for youth who use substances. ${ }^{15}$ Our study suggests that this group is medically vulnerable, with high rates of morbidity and medical co-morbidity, as well as socially vulnerable, as evidenced by the number of homeless youth and those considered as wards of the state. Many youth presented to the ED without any social supports (only 30\% were accompanied by a family member or friend), and, in the majority of cases, EMS was activated by a non-acquaintance.
Approximately $17 \%$ of youth sustained an injury or an assault prior to their ED presentation, and the majority $(60 \%)$ required emergent physician assessment (CTAS 1 or 2). This, coupled with the fact that youth substance use is known to predict problematic substance use and poor psychosocial functioning as an adult, ${ }^{19-21}$ suggests that early identification and treatment, which is beyond the acute medical management for youth presenting to the ED with a substance use disorder, are urgently needed.

Although screening/brief intervention/referral-totreatment has been advocated for routine use in the ED setting, ${ }^{15,22}$ such an approach has not been widely implemented. This may be due to the fact that some ED providers feel that asking about alcohol consumption may be seen as offensive, and many feel pressured by a perceived lack of time and resources to deal with these issues. ${ }^{23}$ Despite this, alcohol- and drug-using adolescents have clearly been identified as a population that ED care providers need to be able to expertly manage and link to appropriate resources. ${ }^{22,24}$ Despite these recommendations, the majority of patients were not admitted, and only a minority of patients in our study was referred to mental health or substance use services at the time of ED or hospital discharge.

Emergency physicians need to be alert to the changing patterns of drug use in their community. Prescription drug misuse is a growing problem in Canada. ${ }^{2,3}$ Canada is the world's second largest per capita consumer of opioids, one of the most dangerous classes of prescription medications that is used recreationally. ${ }^{3}$ Youth have been identified at particularly high risk of harm when using these substances, and existing research has shown that youth view prescription drugs as "safer" than illegal drugs. ${ }^{25}$ Of concern in our study is that, although only $6 \%$ of presentations were related to prescription drug use, this group had the highest admission rate $(38 \% \mathrm{v}$. an average admission rate of $6.1 \%$ for single-drug ingestions).

Despite awareness of both the immediate and delayed burden of medical and social illness faced by these patients, there remains room for improvement in their care in the ED. Similarly, community-based interventions (e.g., drug screening by primary care providers or school personnel) could be tailored, based on the observed trends in this study. Implementing a systematic way to identify high-risk substance using adolescents and creating connections that ensure a seamless transition from acute care to appropriate 
community-based treatment options are urgently needed to prevent future morbidity and mortality. While this is an extremely complex problem that cannot be easily solved, the presentation of these youth to the ED must, at the very least, be used as an opportunity to connect them with resources aimed at prevention, including mental health and addictions counseling or a social worker.

\section{LIMITATIONS}

Limitations for this study review include many that are inherent to medical record review methodology. These include missing information due to incomplete charts, lack of standardization of the records, and records missed due to incorrect coding. Response bias may have affected this retrospective study due to the sensitive nature of the patients' medical presentations and their potential reluctance to disclose all details to the treating team. Further, the potential inability for patients to accurately describe what substances that they ingested might have introduced ascertainment bias. Our data were not re-abstracted to check for inter-rater reliability, and one abstractor was not blinded to study hypothesis, due to financial constraint of the study. The repeat visits for $8 \%(53 / 641)$ of our included patients were treated as unique events, because per-patientbased statistical calculations were beyond the scope of this project. Given that the data are from 2007-2009, it is possible that drug abuse trends have changed in the interim. Finally, this study reflects one Canadian pediatric centre and, as such, is not necessarily generalizable to all other centres.

\section{CONCLUSION}

Youth who presented to the ED for substance use represented a socially vulnerable population whose use of recreational substances resulted in high medical acuity and significant morbidity. Such youth required acute medical resources and spent significant time in the hospital and ED. Health professionals in the ED may not be meeting their follow-up needs, given how few are documented as having been referred to social workers and mental health services. As such, it behooves us to think about referral systems and how we treat patients with acute intoxication in the ED. Further study of the economic impact of these presentations should be considered, as should the development and study of intervention programs for these highrisk youth.

Acknowledgements: We would like to thank Yvonne Klatt for her assistance in data abstraction, Hitesh Bhatt for his statistical support, and Melissa Gutland for her administrative support for this project. We would also like to acknowledge the Women and Children's Health Research Institute (WCHRI) for their financial support of this research through the WCHRI Trainee Grant Competition.

Competing interests: This project was funded through the Women and Children's Health Research Institute Trainee Grant Program (2010). Dr. Newton receives New Investigator funding from the CIHR (Canadian Institutes of Health Research) and Dr. Rosychuk receives funding from AHFMR (Alberta Heritage Foundation for Medical Research).

\section{REFERENCES}

1. Summary of results from the 2010-11 youth smoking survey. Updated 2012. Available at: http://www.hc-sc.gc.ca/hc-ps/ tobac-tabac/research-recherche/stat/_survey-sondage_20102011/result-eng.php (accessed November 19, 2013).

2. Fischer B, Rehm J, Goldman B, Popova S. Non-medical use of prescription opioids and public health in Canada: an urgent call for research and interventions development. Can 7 Public Health 2008;99(3):182-4.

3. National Advisory Committee on Prescription Drug Misuse. First do no harm: responding to Canada's prescription drug crisis. Updated 2013. Available at: http://www.ccsa.ca/ 2013\%20CCSA\%20Documents/Canada-Strategy-Prescript ion-Drug-Misuse-Report-en.pdf (accessed November 20, 2013).

4. Popova S, Rehm J, Patra J, et al. Illegal drug-attributable morbidity in Canada 2002. Drug Alcobol Rev 2007;26(3): 251-63.

5. Black K, Asbridge M, Lea S. An overview of injuries to adolescents and young adults related to substance use: data from Canadian emergency departments. CFEM 2009; 11(4):330-6.

6. Rehm J, Gnam W, Popova S, et al. The costs of alcohol, illegal drugs, and tobacco in Canada, 2002. I Stud Alcobol Drugs 2007;68(6):886-95.

7. Slaughter L. Involvement of drugs in sexual assault. 7 Reprod Med 2000;45(5):425-30.

8. Hall JA, Moore CB. Drug facilitated sexual assaulta review. 7 Forensic Leg Med 2008;15(5):291-7.

9. Chun TH, Spirito A, Hernandez L, et al. The significance of marijuana use among alcohol-using adolescent emergency department patients. Acad Emerg Med 2010;17(1): 63-71.

10. Rome ES, Rybicki LA, Durant RH. Pregnancy and other risk behaviors among adolescent girls in Ohio. 7 Adolesc Health 1998;22(1):50-5.

11. McMahon EM, Reulbach U, Corcoran P, et al. Factors associated with deliberate self-harm among Irish adolescents. Psychol Med 2010;40(11):1811-9. 
12. Hingson $\mathrm{RW}, \mathrm{Zha} W$. Age of drinking onset, alcohol use disorders, frequent heavy drinking, and unintentionally injuring oneself and others after drinking. Pediatrics 2009;123(6):1477-84.

13. Poulin C, Graham L. The association between substance use, unplanned sexual intercourse and other sexual behaviours among adolescent students. Addiction 2001;96(4): 607-21.

14. Hoare J. Drug misuse declared: findings from the 2008/09 British crime survey. England of Wales. 2009. Available at: http:// webarchive.nationalarchives.gov.uk/20110220105210/rds.homeoffice.gov.uk/rds/pdfs09/hosb1209.pdf (accessed November 20, 2013).

15. Burke PJ, O’Sullivan J, Vaughan BL. Adolescent substance use: brief interventions by emergency care providers. Pediatr Emerg Care 2005;21(11):770-6.

16. The City of Edmonton. 2013. Available at: http://www. edmonton.ca/city_government/municipal-census.aspx (accessed November 20, 2013).

17. Murray M, Bullard M, Grafstein E, CTAS National Working Group, CEDIS National Working Group. Revisions to the Canadian emergency department triage and acuity scale implementation guidelines. CFEM 2004; $6(6): 421-7$.

18. Harris PA, Taylor R, Thielke R, et al. Research electronic data capture (REDCap)-a metadata-driven methodology and workflow process for providing translational research informatics support. 7 Biomed Inform 2009;42(2): 377-81.

19. Sussman S, Skara S, Ames SL. Substance abuse among adolescents. Subst Use Misuse 2008;43(12-13):1802-28.

20. Bonomo YA, Bowes G, Coffey C, et al. Teenage drinking and the onset of alcohol dependence: a cohort study over seven years. Addiction 2004;99(12):1520-8.

21. Rohde P, Lewinsohn PM, Seeley JR, et al. Psychosocial functioning of adults who experienced substance use disorders as adolescents. Psychol Addict Behav 2007;21(2): 155-64.

22. Newton AS, Gokiert R, Mabood N, et al. Instruments to detect alcohol and other drug misuse in the emergency department: a systematic review. Pediatrics 2011;128(1): e180-92.

23. Mabood N, Zhou H, Dong K, et al. Attitudes and beliefs towards patients with hazardous alcohol use: a systematic review. ISRN Emerg Med 2012;2012:1-10, doi: $\underline{10.5402 / 2012 / 837380 .}$.

24. Hollman D, Alderman E. Substance abuse counseling. Pediatr Rev 2007;28(9):355-7.

25. Twombly EC, Holtz KD. Teens and the misuse of prescription drugs: evidence-based recommendations to curb a growing societal problem. 7 Prim Prev 2008;29(6): 503-16. 